Inflammatory bowel disease

\section{Risks and benefits of azathioprine therapy}

\section{P B McGovern, D P Jewell}

The risk of lymphoma may be increased by about fourfold in patients with inflammatory bowel disease treated with thiopurines. The increased risk could be a result of the medications, the severity of the underlying disease, or a combination of the two

$\mathrm{T}$ he benefits of the thiopurines, azathioprine (AZA), and 6-mercaptopurine (6-MP) in maintaining remission and corticosteroid sparing in inflammatory bowel disease (IBD) are beyond doubt. However, adverse events as well as benefits should always be considered when the effectiveness of any treatment is being evaluated. The "short term" side effects of thiopurines have been well documented and there have been a number of studies examining the role of thiopurine methyltransferase activity in predicting the risk of these side effects. In this issue of Gut, Kandiel and colleagues ${ }^{1}$ address the difficult issue of the long term risk of lymphoma associated with thiopurine therapy (see page 1121). Using the technique of meta-analysis of cohort studies, the authors concluded that there was about a fourfold increase in lymphoma in IBD patients treated with thiopurines. The headline from this study will cause alarm among patients and clinicians alike but, as in all studies, closer examination of the limitations (as acknowledged by the authors) of the study is necessary before firm conclusions can be drawn. Meta-analyses have their own particular methodological problems and are only as good as the constituent studies. The authors demonstrated heterogeneity between the studies suggesting that the studies were "different" with respect to study population or methodology. The consistent risk of lymphoma, even after sensitivity analyses (to ensure that rogue studies had not radically influenced the risk), is somewhat reassuring but the negative correlation between size of cohort and risk of lymphoma is of concern.

Association does not prove causation and it is possible that the demonstrated risk is with IBD itself and not with thiopurines. The authors cite evidence that there is no association between IBD and lymphoma but other data suggest that there may be a significant but small association. ${ }^{23}$ The authors address this by demonstrating an increased lymphoma risk in patients treated with thiopurines when compared with IBD patients who had not received thiopurines. Thiopurine use however may simply be a marker for more severe disease which may itself increase the risk of lymphoma. This effect of disease severity may be small and already underpowered studies may have missed such a relationship. The studies included in this analysis were mainly from tertiary referral centres and the largest population based study found no thiopurinelymphoma association, further raising the possibility of a disease severity bias. Smoking has a deleterious effect on Crohn's disease ${ }^{4}$ and smokers are, in theory at least, more likely to require secondline therapies for Crohn's disease and are also at increased risk of Hodgkin's lymphoma, ${ }^{5}$ thereby adding more complexity to the demonstrated association.

Should thiopurines be used more judiciously or even stopped? Quite the contrary! We believe that the case of thiopurines and lymphoma remains unproven but even if the relationship is proved to be causative, the data suggest that thiopurines are of benefit in IBD. The suggested fourfold risk is likely to be an exaggeration, and riskbenefit model analyses have suggested that a 10 -fold risk is necessary for the overall effect of thiopurines in IBD to be detrimental. ${ }^{6}$ The alternatives are not without significant risk. These include uncontrolled inflammation, repeated courses of corticosteroids, alternative immunosuppressants (methotrexate and infliximab administration have also been associated with an increased risk of lymphoma), and surgery. So what should clinicians tell their patients? The risk of lymphoma in IBD patients receiving thiopurines is small, if there at all, but the benefits far outweigh the risks.

Study data suggest that thiopurines are effective for up to five years ${ }^{7}$ and indeed anecdotal evidence suggests that they may be effective for much longer than that. Vigilance and further large scale studies will be required in the future to ensure that long term thiopurine therapy is not associated with a significant risk of neoplasia. For the present, clinicians should be reassured that, on the whole, these drugs are safe in the long term and are of significant benefit to patients with IBD, and their appropriate use should be actively encouraged.

Gut 2005;54:1055.

doi: 10.1136/gut.2004.053231

\section{Authors' affiliations}

Dr D P B McGovern, The Wellcome Trust Centre for Human Genetics, Headington, Oxford, UK

D P Jewell, Gastroenterology Unit, University of Oxford, Oxford, UK

Correspondence to: Dr D P B McGovern, The Wellcome Trust Centre for Human Genetics, Roosevelt Drive, Headington, Oxford OX3 7BN, UK; dermoł@well.ox.ac.uk

Conflict of interest: None declared.

\section{REFERENCES}

1 Kandiel A, Fraser AG, Korelitz BI, et al. Increased risk of lymphoma among inflammatory bowel disease patients treated with azathioprine and 6-mercaptopurine. Gut 2005;54:1121-5.

2 Loftus E, Tremaine W, Habermann T. Risk of lymphoma in inflammatory bowel disease. Am J Gastroenterol 2000;95:2308-12.

3 Bernstein C, Blanchard J, Kliewer E, et al. Cancer risk in patients with inflammatory bowel disease: a population-based study. Cancer 2001;91:854-62.

4 Sutherland LR, Ramcharan S, Bryant H, et al. Effect of cigarette smoking on recurrence of Crohn's disease. Gastroenterology 1990;98:1123-8.

5 Besson H, Renaudier P, Merrill RM, et al. Smoking and non-Hodgkins lymphoma: a case-contro study in the Rhone-Alpes region of France. Cancer Causes Control 2003;14:381-9.

6 Lewis J, Schwartz S, Lichtenstein GR. Azathioprine for maintenance of remission in Crohn's disease: benefits outweigh the risk of lymphoma. Gastroenterology 2000;118:1018-24

7 Lemann M, Bouhnik Y, Colombel J, et al. Randomised double-blind placebo-controlled multi-centre azathioprine withdrawl trial in Crohn's disease. Gastroenterology 2002; 122:A23. 


\section{$5-\mathrm{HT}_{3}$ receptor antagonists ameliorate fatigue: so much potential, so little knowledge!}

\section{N M Barnes}

\section{There is growing evidence that $5-\mathrm{HT}_{3}$ receptor blockade will benefit patients with fatigue. Further research is needed to determine the mechanism underlying this widespread clinically important symptom and therapies may be derived from targeting the 5-HT system}

D espite a high prevalence with massive socioeconomic implications, fatigue per se, or as a symptom of a diagnosed condition, remains poorly understood. Much of the evidence available arises from measurement of biochemicals or proteins; alterations in which may be primary or secondary to the symptom, or indeed associated with another aspect of an underlying disease. However, an increasing body of evidence implicates an altered central 5-HT (5-hydroxytryptamine; serotonin) system. Although apparent inconsistencies are evident (for example, see Hartz and colleagues ${ }^{1}$ ), elevated 5-HT neurotransmission appears most likely. ${ }^{2-5}$ Numerous distinct receptors have evolved to transduce 5-HT signalling. The majority of these receptors (at least 13) are G protein coupled receptors (GPCRs) but, unusual for monoamine neurotransmitters, an additional receptor, the $5-\mathrm{HT}_{3}$ receptor, is a member of the cys-cys loop ligand gated ion channel superfamily; other members being the nicotinic acetylcholine receptor, the $\mathrm{GABA}_{\mathrm{A}}$ receptor, and the glycine receptor. ${ }^{6}$ The $5-\mathrm{HT}_{3}$ receptor is predominantly expressed by central neurones and peripheral nerves and is known to mediate fast synaptic neurotransmission in the brain.

The clinical availability of $5-\mathrm{HT}_{3}$ receptor antagonists offers an opportunity to probe further for roles for this receptor. In this issue of Gut, Piche and colleagues ${ }^{7}$ provide further support for the use of $5-\mathrm{HT}_{3}$ receptor antagonists to alleviate fatigue, in this case arising from hepatitis $\mathrm{C}$ infection (see page 1169). This builds on previous observations where these compounds have reduced fatigue in uncontrolled studies with small numbers of patients. ${ }^{89}$ The double blind placebo controlled trial with originally 36 patients demonstrated that chronic administration of the selective $5-\mathrm{HT}_{3}$ receptor antagonist ondansetron (Zofran; a relatively low oral dose of $4 \mathrm{mg}$ twice daily for 30 days) improved the level of fatigue in patients relative to placebo (although a significant positive placebo response was also evident at one of the time points). As acknowledged by the authors, they selected patients with relatively high levels of fatigue, which may have allowed a greater scope for the detection of drug induced effects in this symptom that is notoriously difficult to quantify. Interestingly, depressive symptoms in patients also improved. Given the strong association of fatigue as a symptom of depressed patients, it would be pertinent to investigate whether the ondansetron induced reduction in the two symptoms are interrelated. Of further note, both the reduction in fatigue and depression were also evident 30 days after discontinuation of the drug treatment, suggesting that plastic changes may have occurred, as has been postulated for more traditional antidepressant therapies. It may be relevant, however, that another symptom often associated with hepatic disease, pruritus, also likely to be centrally mediated, appears responsive to $5-\mathrm{HT}_{3}$ receptor antagonists. ${ }^{10} 11$

From their early development in the mid- to late $1980 \mathrm{~s}$, the selective $5-\mathrm{HT}_{3}$ receptor antagonists have been hailed for their potential clinical utility. Much of the initial impetus for their synthesis and development came from the antiemetic efficacy of metoclopramide. At high dosage, metoclopramide afforded additional protection from the nausea and vomiting associated with aggressive anticancer treatment that appeared to correlate with the relatively low affinity to antagonise $5-\mathrm{HT}_{3}$ receptors (for review see Barnes and colleagues ${ }^{12}$ ). The strategy was vindicated with the substantial antiemetic efficacy of selective $5-\mathrm{HT}_{3}$ receptor antagonists such as ondansetron (Zofran), granisetron (Kytril), and tropisetron (Navoban).

Soon after the availability of selective $5-\mathrm{HT}_{3}$ receptor antagonists, pioneering work by Costall and Naylor, as well as others, demonstrated that these compounds displayed therapeutic potential in numerous animal models predictive of, for instance, anxiolytic, antipsychotic, and cognitive enhancing actions. The subsequent clinical trials however were largely disappointing and curtailed the development of these compounds for these indications (for reviews see Barnes and Sharp ${ }^{6}$ and Costall and Naylor $\left.{ }^{13}\right)$. Clear reasons for these failures remain to be elucidated. Perhaps the animal models simply did not accurately mimic the human diseases? An often quoted explanation is that the unusual bell shaped dose-response curve often evident with $5-\mathrm{HT}_{3}$ receptor antagonists (that is, efficacy is lost at higher dosages) necessitates a wide dose range to prove the negative (that is, to prove that there really is no effect). This phenomenon still awaits a mechanistic rationalisation.

However, perhaps the failure simply reflects the different pattern of forebrain expression in humans compared with laboratory animals. For instance, the human cerebral cortex displays relatively low levels of $5-\mathrm{HT}_{3}$ receptor binding sites, unlike rodents. ${ }^{14-18}$ In contrast, human extrapyramidal regions such as the caudate nucleus and putamen display relatively high levels of $5-\mathrm{HT}_{3}$ receptor binding sites, whereas little corresponding expression is evident in rodents. ${ }^{14-18}$ The area is further complicated by the apparent species specific expression of individual $5-\mathrm{HT}_{3}$ receptor subunits. Thus central expression of the biophysical 5- $\mathrm{HT}_{3 \mathrm{~B}}$ subunit is apparent in human but not rodent brain. ${ }^{19-22}$ The presence of at least three further purported $5-\mathrm{HT}_{3}$ receptor subunits $\left(5-\mathrm{HT}_{3 \mathrm{C}}, 5-\mathrm{HT}_{3 \mathrm{D}}\right.$, and $5-\mathrm{HT}_{3 \mathrm{E}}$ subunits ${ }^{21}$ ) within the human genome, with no corresponding genes identified in rodents, further highlights interspecies differences in the potential expression of different $5-\mathrm{HT}_{3}$ receptor isoforms. This area has received little investigation to date, yet in terms of pharmacology, at least the homomeric $5-\mathrm{HT}_{3 \mathrm{~A}}$ receptor and the heteromeric $5-\mathrm{HT}_{3 \mathrm{~A} / 3 \mathrm{~B}}$ receptor appear nearly identical, ${ }^{23}$ although major functional differences are apparent-for instance, the differing ionic selectivity of the ion channel integral with the receptor, with homomeric $5-\mathrm{HT}_{3 \mathrm{~A}}$ receptors displaying high permeability to $\mathrm{Ca}^{2+}$ relative to the heteromeric $5-\mathrm{HT}_{3 \mathrm{~A} / 3 \mathrm{~B}}$ receptor complex. A further difference is the single channel conductance, which is an order of 
magnitude higher for heteromeric $5-\mathrm{HT}_{3 \mathrm{~A} / 3 \mathrm{~B}}$ receptors relative to homomeric $5-\mathrm{HT}_{3 \mathrm{~A}}$ receptors. ${ }^{19}{ }^{24}$

Given these major pattern of expression and functional differences between the human $5-\mathrm{HT}_{3}$ receptor isoforms and their rodent counterparts, it is perhaps not surprising that the behavioural consequences of antagonising forebrain $5-\mathrm{HT}_{3}$ receptors appear to be species dependent. In terms of investigating clinical utility, clearly this problem is bypassed by direct evaluation of $5-\mathrm{HT}_{3}$ receptor function in human volunteers or patients; this strategy identifying the ability of $5-\mathrm{HT}_{3}$ receptor antagonists to reduce fatigue..$^{7-9}$

The growing evidence that $5-\mathrm{HT}_{3}$ receptor blockade will benefit patients with fatigue requires support from large multicentre trials. However, the encouraging signs will further promote research to determine the mechanism(s) underlying this widespread clinically important symptom and suggests that further therapies may be derived from targeting the 5-HT system, a strategy that has already reaped rich rewards. ${ }^{25}$

Gut 2005;54:1056-1057.

doi: 10.1136/gut.2004.063545

Correspondence to: Dr N M Barnes, Cellular and Molecular Neuropharmacology Research Group, Department of Pharmacology, Division of Neuroscience, The Medical School, University of Birmingham, Edgbaston,

Birmingham B15 2TT, UK;

n.m.barnes@bham.ac.uk

Conflict of interest: None declared.

\section{REFERENCES}

1 Hartz AJ, Bentler SE, Brake KA, et al. The effectiveness of citalopram for idiopathic chronic fatigue. J Clin Psychiatry 2003;64:927-35.

2 Wilson WM, Maughan RJ. Evidence for a possible role of 5-hydroxytryptamine in the genesis of fatigue in man: administration of paroxetine, a 5-HT re-uptake inhibitor, reduces the capacity to perform prolonged exercise. Exp Physiol 1992;77:921-4.

3 McGuire J, Ross GL, Price $\mathrm{H}$, et al. Biochemical markers for post-operative fatigue after major surgery. Brain Res Bull 2003;60:125-30.

4 Yamamoto $S$, Ouchi $Y$, Onoe $H$, et al. Reduction of serotonin transporters of patients with chronic fatigue syndrome. NeuroReport 2004; 15:2571-4.

5 Cleare AJ, Messa C, Rabiner EA, et al. Brain 5$\mathrm{HT}_{1 \mathrm{~A}}$ receptor binding in chronic fatigue syndrome measured using positron emission tomography and [ $\left.{ }^{11} \mathrm{C}\right] \mathrm{WAY}-100635$. Biol Psychiatry 2005;57:239-46.

6 Barnes NM, Sharp T. A review of central 5-HT receptors and their function. Neuropharmacology 1999;38:1083-152.

7 Piche T, Vanbiervliet G, Cherikh F, et al. Effect of ondansetron, a $5-\mathrm{HT}_{3}$ receptor antagonist, on fatigue in chronic hepatitis $\mathrm{C}$ : a randomised double blind, placebo controlled study. Gut 2005; 54: 1169-73.

8 Jones EA. Relief from profound fatigue associated with chronic liver disease by long-term ondansetron therapy. Lancet 1999;354:397.

9 Spath M, Welzel D, Farber L. Treatment of chronic fatigue syndrome with 5-HT3 receptor antagonists-preliminary results. Scand J Rheumatol 2000;113(suppl):72-7.

10 Schworer H, Hartmann H, Ramadori G. Relief of cholestatic pruritus by a novel class of drugs: 5hydroxytryptamine type $3\left(5-\mathrm{HT}_{3}\right)$ receptor antagonists: effectiveness of ondansetron. Pain 1995;61:33-7.

11 Muller C, Pongratz S, Pidlich J, et al. Treatment of pruritus in chronic liver disease with the 5 hydroxytryptamine receptor type 3 antagonist ondansetron: a randomized, placebo-controlled double-blind cross-over trial. Eur J Gastroenterol Hepatol 1998; 10:865-70.

12 Barnes JM, Barnes NM, Costall B, et al. The development of $5-\mathrm{HT}_{3}$ receptor antagonists as anti-emetics. Pharm J 1991;246:112-14.
13 Costall B, Naylor RJ. 5- $\mathrm{HT}_{3}$ receptors. Curr Drug Targets CNS Neurol Disord 2004;3:27-37.

14 Barnes JM, Barnes NM, Costall B, et al. Identification and characterisation of $5-\mathrm{HT}_{3}$ recognition sites in human brain tissue. J Neurochem 1989;53:1787-93.

15 Barnes JM, Barnes N M, Champaneria S, et al. Characterisation and autoradiographic localisation of $5-\mathrm{HT}_{3}$ receptor recognition sites identified with $\left[{ }^{3} \mathrm{H}\right]-(\mathrm{S})$-zacopride in the rat forebrain. Neuropharmacology 1990;29: 1037-45.

16 Bufton KE, Steward U, Barber PC, et al Distribution and characterization of the $\left[{ }^{3} \mathrm{H}\right]$ granisetron-labelled $5-\mathrm{HT}_{3}$ receptor in the human forebrain. Neuropharmacology 1993;32:1325-32.

17 Steward L, West KE, Kilpatrick GJ, et al. Labelling of $5-\mathrm{HT}_{3}$ receptor recognition sites in the rat brain using the agonist radioligand $\left[{ }^{3} \mathrm{H}\right]$ metachlorophenylbiguanide. Eur J Pharmacol 1993;243:13-18.

18 Barnes JM, Ge J, Parker RMC, et al. Autoradiographic distribution of $\left[{ }^{3} \mathrm{H}\right]-(\mathrm{S})$ zacopride-labelled $5-\mathrm{HT}_{3}$ receptors in human brain. J Neurol Sci 1996; 144:119-27.

19 Davies PA, Pistis M, Hanna MC, et al. The 5-HT3B subunit is a major determinant of serotoninreceptor function. Nature 1999;397:359-63.

20 Dubin AE, Huvar R, D'Andrea MR, et al. The pharmacological and functional characteristics of the serotonin 5-HT(3A) receptor are specifically modified by a $5-\mathrm{HT}(3 \mathrm{~B})$ receptor subunit. J Biol Chem 1999;274:30799-810

21 Niesler B, Frank B, Kapeller J, et al. Cloning physical mapping and expression analysis of the human $5-\mathrm{HT}_{3}$ serotonin receptor-like genes HTR3C, HTR3D and HTR3E. Gene 2003;310:101-11.

22 van Hooft JA, Yakel JL. 5- $\mathrm{HT}_{3}$ receptors in the CNS: 3B or not 3B? Trends Pharmacol Sci 2003:24:157-60

23 Brady CA, Stanford IM, Ali I, et al. Pharmacological comparison of human homomeric $5-\mathrm{HT}_{3 \mathrm{~A}}$ receptors versus heteromeric $5-\mathrm{HT}_{3 \mathrm{~A} / 3 \mathrm{~B}}$ receptors. Neuropharmacology 2001;41:282-4.

24 Kelley SP, Dunlop JI, Kirkness EF, et al. A cytoplasmic region determines single-channe conductance in $5-\mathrm{HT}_{3}$ receptors. Nature 2003:424:321-4.

25 Jones BJ, Blackburn TP. The medical benefit of 5 HT research. Pharmacol Biochem Behav 2002;71:555-68.

\section{Predicting mortality by the Glasgow alcoholic hepatitis score: the long awaited progress?}

\section{H Tilg, A Kaser}

The new Glasgow alcoholic hepatitis score may represent a substantial improvement in clinical phenotyping and could catalyse the development of new treatments in severe alcoholic hepatitis

$\mathrm{S}$ evere alcoholic hepatitis is associated with a high mortality and the presence of liver failure, manifested by jaundice, coagulopathy, and often encephalopathy. Whereas insights into the pathophysiology of this devastating disease have improved over the past years, clinical progress in the last two decades has been minor. For more than two decades, steroids have remained the only moderately effective treatment option. One key confounder to most therapy studies has been the use of the discriminant function to identify patients at highest risk of mortality in the absence of better scoring systems more accurately predicting the outcome of severe alcoholic steatohepatitis. The now reported Glasgow alcoholic hepatitis score might represent a substantial improvement in clinical phenotyping and could catalyse the development of new treatments in this disease.

The appearance of steatohepatitis is an important rate limiting step in the development of progressive alcoholic liver disease. One month mortality rates of $40-50 \%$ have been reported in patients hospitalised with acutely decompensated liver disease due to alcohol induced steatohepatitis. ${ }^{1}$ Patients with severe alcoholic steatohepatitis typically present with fever, hepatomegaly, jaundice, and anorexia. The presence of liver failure manifested by 
coagulopathy, jaundice, and/or encephalopathy is an indicator of poor outcome, usually highlighting the presence of limited hepatic functional reserve. Approximately $40-50 \%$ of patients have ascites and tender hepatomegaly is common. Leucocytosis is frequent and correlates with the severity of hepatic injury. ${ }^{2}$ Neutrophilic infiltration is commonly seen on liver biopsy and these cells may play an important role in the hepatic injury. Although the diagnosis can be confirmed by liver biopsy, clinical and laboratory features are often adequate for establishing the diagnosis. Absolute values for serum aspartate and alanine aminotransferases are almost always <400 IU/l and higher concentrations should raise suspicion of concurrent liver injury due to viral or other aetiologies. Combined cirrhosis and alcoholic hepatitis is often associated and has the worst prognosis. ${ }^{3}$

The severity of this disease is best correlated with serum bilirubin level and prothrombin time after vitamin $\mathrm{K}$ administration. ${ }^{4}$ As part of a seminal clinical study on corticosteroid therapy in severe alcoholic hepatitis, the discriminant function (DF) formula (which includes prothrombin time and bilirubin levels) was derived to predict disease severity and individual mortality risk in these patients. ${ }^{4}$ This DF was later modified in the context of a further placebo controlled corticosteroid trial. ${ }^{5} \mathrm{~A}$ modified discriminant function $(\mathrm{mDF})$ of $>32$ and/or the presence of encephalopathy in placebo treated patients in this latter study was associated with a $65 \% 28$ day survival. A recent re-analysis confirmed this finding and also demonstrated that patients with a score $<32$ had a survival of $93 \%{ }^{6}$ Therefore, this cut off value of 32 has been used and recommended as the threshold to consider corticosteroid treatment. ${ }^{7}$ More recently, the MELD score has been applied to alcoholic hepatitis. In a study of 34 patients with a MELD score of $>11$, there was a $45 \% 30$ day survival while those with a score $\leqslant 11$ had a survival of $96 \%{ }^{8}$ The MELD score includes creatinine values as both blood urea and creatinine values increase and may reflect severity in severe alcoholic steatohepatitis. They predict the development of the hepatorenal syndrome. A polymorph leucocytosis is found $(>15$ $\left.20 \times 10^{9} / 1\right)$ in proportion to the severity of the disease. ${ }^{9}$

\section{DO WE NEED BETTER SCORING SYSTEMS IN ALCOHOLIC HEPATITIS? \\ (i) We need a simple test which can be calculated at the bedside}

Calculation of $\mathrm{mDF}$ relies on the absolute value of the prothrombin time and there exists significant variation in the absolute values of prothrombin time obtained using different assays in different countries (for example, UK, USA). This may thereby affect the validity of the mDF score in countries such as the UK where a greater severity score will be generated based on the prothrombin time. This creates a definite inaccuracy in the mDF value and limits its translation between different facilities. Furthermore, the presence of encephalopathy has often been included when making a treatment decision, in addition to just calculating the mDF. This is problematic, as encephalopathy is very subjective in its milder forms. Kulkarni and colleagues ${ }^{11}$ have also shown that addition of encephalopathy displayed a slight increase in sensitivity but a dramatic decrease in specificity compared with the mDF. Therefore, encephalopathy is not an attractive parameter influencing treatment decisions (although this reflects current practice). The MELD score is also difficult to calculate at the bedside and inclusion of creatinine in the MELD may also limit its usefulness as creatinine values will be underestimated in the context of hyperbilirubinaemia unless corrected. In addition, it has been demonstrated that the MELD score is not superior to $\mathrm{mDF}$ in this population. ${ }^{8}$ Recently, the MELD score has been demonstrated to be a useful score for a panel of chronic advanced liver diseases, including severe alcoholic hepatitis, albeit it is only equivalent to the ChildTurcotte-Pugh score in predicting survival. $^{10}$ Both scoring systems (mDF, MELD) use highly relevant variables in severe alcoholic liver disease but ignore other aspects of this disease, such as inflammatory parameters. Therefore, a score including a more complex panel of clinical variables but which can be easily assessed at the bedside would be highly desired.

\section{(ii) We need a score which} identifies as many patients as possible with a high mortality risk Apart from the positive reports on the relevance of an mDF cut off value of $32,{ }^{\circ}$ its accuracy in predicting survival has been repeatedly questioned. Kulkarni et al recently reported that patients with a low $\operatorname{mDF}(\leqslant 32)$ also had significant mortality, approaching $17 \% .{ }^{11}$ In this study, the mDF was only moderately sensitive $(66.7 \%)$ and specific $(61.7 \%)$. Considering the considerable mortality in patients with a DF $\leqslant 32$, it would be reasonable to consider treatment options for these patients also. In addition, even more importantly, re-evaluation of current criteria for assessing disease severity is needed to more accurately identify patients at risk for short and long term mortality.

Given the relatively poor ability of the mDF to predict short term mortality, a new indicator of mortality and severity was eagerly awaited. Forrest and colleagues $^{12}$ report in this issue of Gut the derivation of a score termed the Glasgow alcoholic hepatitis score (GAHS) based on a large patient population and its validation using a new and independent set of patients (see page 1174). Importantly, overall survival was studied in a large patient population $(\mathrm{n}=241)$ until day 84, allowing more accurate judgement about the clinical course and not only short term survival (day 28). In their analysis, $\mathrm{mDF}$ was highly sensitive in the prediction of death from alcoholic hepatitis but lacked specificity. This was dramatic as it incorrectly predicted the outcome at 28 days after admission in $51 \%$ of cases. By multiple stepwise logistic regression they developed the key factors for later deriving and developing their GAHS. All of these factors (age, white blood cell count, blood urea, prothrombin time ratio, and bilirubin) are well known from other studies to affect mortality but have never been used in combination to calculate survival. ${ }^{13-15}$ In their analysis, patients with an admission $\mathrm{mDF} \geqslant 32$ had a survival of $64 \%$ and $52 \%$ at days 28 and 84 , respectively, whereas patients with a GAHS $\geqslant 9$ had a survival of $46 \%$ and $40 \%$ at days 24 and 84 , respectively. The GAHS at days 1 and 7 was significantly more accurate in predicting day 24 and 84 outcome than the mDF and had an impressive better overall accuracy. Furthermore, the GAHS was also significantly more accurate than the MELD score in predicting short and long term survival.

\section{(iii) Future developments and aspects which might be considered in further new scores}

Whereas the new GAHS for the first time includes an inflammatory parameter (white blood cell count) which is important for such a highly inflammatory disease, other inflammatory and immune parameters may also be helpful for future scoring systems. C reactive protein levels and plasma levels of tumour necrosis factor soluble receptors p55 and p75 have been demonstrated to correlate with short and long term survival. ${ }^{16-18}$ On the other hand, extracellular matrix markers such as laminin might be accurate markers predicting survival in these patients. ${ }^{19}$ Apart from immune markers, early changes in bilirubin levels and major changes in portal flow are prognostic factors in 
patients with severe alcoholic steatohepatitis treated with corticosteroids. ${ }^{20} 21$

Treatment of severe alcoholic hepatitis has hardly progressed in recent years. Lack of a scoring system with appropriate overall accuracy may have contributed to this poor situation by confounding clinical studies. Current clinical strategy favours a "watch and wait" strategy awaiting disease progression in those patients incorrectly identified as low risk by a low DF $(\leqslant 32)$. Such a strategy may be counterproductive in a severe disease with high mortality and is an uncommon strategy in modern medicine. In addition, patients with a DF $>32$ often have contraindications for steroid treatment and cannot receive this treatment. Therefore, the new score presented here raises hopes of a more accurate clinical tool to predict survival and therefore advance the field, initiating new studies with innovative treatment modalities reflecting current pathophysiology. In conclusion, the new Glasgow alcoholic hepatitis score might indeed be the long awaited progress in this field.

\section{ACKNOWLEDGEMENT}

This work was supported by the Austrian Science Fund (P 15783 and P17447).

Gut 2005;54:1057-1059.

doi: $10.1136 /$ gut.2004.063420

\section{.......................}

\section{Authors' affiliations}

H Tilg, A Kaser, Department of Medicine, Division of Gastroenterology and Hepatology, University Hospital Innsbruck, Austria
Correspondence to: Dr H Tilg, Department of Medicine, Division of Gastroenterology and Hepatology, University Hospital Innsbruck, Anichstrasse 35, 6020 Innsbruck, Austria; Herbert.Tilg@uibk.ac.at

Conflict of interest: None declared.

\section{REFERENCES}

1 Tome S, Lucey MR. Review article: current management of alcoholic liver disease. Aliment Pharmacol Ther 2004:19:707-14.

2 Orrego H, Blake JE, Blendis LM, et al. Prognosis of alcoholic cirrhosis in the presence and absence of alcoholic hepatitis. Gastroenterology 1987:92:208-14.

3 Chedid A, Mendenhall CL, Gartside P, et al. Prognostic factors in alcoholic liver disease. VA Cooperative Study Group. Am J Gastroenterol 1991:86:210-16

4 Maddrey WC, Boitnott JK, Bedine MS, et al. Corticosteroid therapy of alcoholic hepatitis. Gastroenterology 1978;75:193-9.

5 Carithers RL Jr, Herlong HF, Diehl AM, et al Methylprednisolone therapy in patients with severe alcoholic hepatitis. A randomized multicenter trial. Ann Intern Med 1989; 1 10:685-90.

6 Mathurin P, Mendenhall CL, Carithers RL Jr, et al. Corticosteroids improve short-term survival in patients with severe alcoholic hepatitis $(\mathrm{AH})$ : individual data analysis of the last three randomized placebo controlled double blind trials of corticosteroids in severe $\mathrm{AH}$. J Hepatol 2002;36:480-7

7 McCullough AJ, O'Connor JF. Alcoholic liver disease: proposed recommendations for the American College of Gastroenterology. Am J Gastroenterol 1998.93.2022-36.

8 Sheth M, Riggs M, Patel T. Utility of the Mayo endstage liver disease (MELD) score in assessing prognosis of patients with alcoholic hepatitis. BMC Gastroenterol 2002;2:2.

9 Stewart SF, Day CP. The management of alcoholic liver disease. J Hepatol 2003;38(suppl 1):S2-13

10 Said A, Williams J, Holden J, et al. Model for end stage liver disease score predicts mortality across a broad spectrum of liver disease. J Hepatol 2004;40:897-903.
11 Kulkarni K, Tran T, Medrano M, et al. The role of the discriminant factor in the assessment and treatment of alcoholic hepatitis. J Clin Gastroenterol 2004:38:453-9.

12 Forrest EH, Evans CDJ, Stewart S, et al. Analysis of factors predictive of mortality in alcoholic hepatitis and derivation and validation of the Glasgow alcoholic hepatitis score. Gut 2005:54:1174-9.

13 Kumashiro R, Sata M, Ishii K, et al. Prognostic factors for short-term survival in alcoholic hepatitis in Japan: analysis by logistic regression. Alcohol Clin Exp Res 1996;20(suppl 9): 383A-6A.

14 Mathurin P, Duchatelle V, Ramond MJ, et al. Survival and prognostic factors in patients with severe alcoholic hepatitis treated with prednisolone. Gastroenterology 1996; 110:1847-53.

15 Dufour DR, Lott JA, Nolte FS, et al. Diagnosis and monitoring of hepatic injury. II.

Recommendations for use of laboratory tests in screening, diagnosis, and monitoring. Clin Chem 2000;46:2050-68.

16 Fujimoto $M$, Uemura $M$, Kojima $\mathrm{H}$, et al. Prognostic factors in severe alcoholic liver injury. Nara Liver Study Group. Alcohol Clin Exp Res 1999;23(suppl):33-8S

17 Naveau S, Emilie D, Balian A, et al. Plasma levels of soluble tumor necrosis factor receptors p55 and p75 in patients with alcoholic liver disease of increasing severity. $J$ Hepatol 1998;28:778-84.

18 Spahr L, Giostra E, Frossard JL, et al. Soluble TNF-R1, but not tumor necrosis factor alpha, predicts the 3-month mortality in patients with alcoholic hepatitis. J Hepatol 2004;41:229-34.

19 Castera L, Hartmann DJ, Chapel F, et al. Serum laminin and type IV collagen are accurate markers of histologically severe alcoholic hepatitis in patients with cirrhosis. $J$ Hepatol 2000;32:412-8.

20 Mathurin P, Abdelnour M, Ramond MJ, et al. Early change in bilirubin levels is an importan prognostic factor in severe alcoholic hepatitis treated with prednisolone. Hepatology 2003;38: 1363-9

21 Duvoux C, Radier C, Roudot-Thoraval F, et al. Low-grade steatosis and major changes in portal flow as new prognostic factors in steroid-treated alcoholic hepatitis. Hepatology 2004;40:1370-8.

2nd annual BSG-AGA research meeting "The pathogenesis and prevention of oesophageal and gastric adenocarcinoma"

This meeting will take place in the Medical Sciences Teaching Centre, South Parks Road, Oxford, on 1-2 September 2005. The closing date for applications is Wednesday 10 August 2005. The speakers are leading USA and UK clinicians and scientists in the field. There will also be abstract presentations. The meeting will have a strictly limited number of attendees to ensure a workshop atmosphere and vibrant discussion.

The cost for the meeting, including accommodation at Wadham College for Wednesday 31 August - Thursday 1 September and a dinner at Wadham College on 1 September, is only $£ 140$ or $\$ 250$.

We encourage people to submit abstracts, although this is not in any way compulsory. Depending on the number submitted, we may be willing to consider late submissions. For full details, a programme, and an application form please visit the BSG website at www.bsg.org.uk. Alternatively please email: simon.travis@orh.nhs.uk or victoria.mcneile@ ndm. ox.uk or phone Simon Travis on +44 (0)1865 224829 . 